\title{
Analysis and Evaluation of Taiwan Water Shortage Factors
}

\section{and Solution Strategies}

\author{
Associate Prof. Ching-Yu Wang (Corresponding author) \\ Institute of Political Economy \\ National Cheng Kung University of Taiwan \\ 1, Ta Shea Road, Tainan, Taiwan \\ Tel: 886-6-6-275-7575-50218Ｅ-mail: wangcy@mail.ncku.edu.tw
}

\author{
Wang, Jhen-Bin \\ Master of Political Science \\ National Cheng Kung University \\ 1, Ta Shea Road, Tainan, Taiwan
}

\begin{abstract}
Water resources are precious but limited natural possessions and significant to people's livings. If the water resources could not be allocated well, the related problems will grow. The water shortage problems are not only related to rainfall, geographic landform, climate, populations, and economic activities, but also allocation, supply, and management of water resources. Hence, water shortage has become an important issue in our country.

This study aims to discuss the factors of water shortage from the viewpoints of political-economics, nature, and management. Natural factors cover special geographic structure, geological structure, and climate change. Management factors include sediment deposit, water turbidity, soil conservation, water nutrition, pipeline leaking, water pollution, water waste, and water organizations. From the management perspective, the importance of water shortage factors is assessed to understanding the critical factors. The analytic hierarchy process was used to evaluate the water shortage factors to promote the rationalization of strategy formulation. The results show that higher important facts are water waste, soil conservation, and pipeline leaking.
\end{abstract}

Keywords: Water shortage factors, Solution strategies, Analytic hierarchy process, Synthesized Judgments

\section{Introduction}

\subsection{The Background and Motivation}

On August 24-25, 2004 Typhoon Aere hit Taiwan with the abundant rainfall, a great deal of silt-carrying water accidentally brought into Shihmen Reservoir, and raw water turbidity was too heavy to have water purification functioned normally. Nearly 200 million people in Taoyuan had lived without water for 12 days; such case of "heavy rain led to water shortage," once occurred in Taichung after the "1983 Flood", when Typhoon Mindulle brought abundant water breaking steel cables of Li-Yu-Tan Reservoir's sluice, blocking the outlet. Millions of people in Taichung lacked of water for more than 10 days in a predicament everywhere. As the "88 Flood" in 2009 occurred, severe raw water turbidity in the southern Taiwan also caused water purification functions to shut down, resulting in the dilemma that a population of about four million in Tainan and Kaohsiung had lived without water for nearly seven days. ( Mo Wen, 2004)

Compared with the routine that Taiwan would have faced water shortage every time it rained little over the years, water shortage actually caused by excessive rain water occurred several times in recent years, which indicates that Taiwan's water shortage problem comes from not that it rains too little, but rains down to the ground afterwards. The issues of how to use and manage it highlight the necessity to review the strategies for Taiwan's water resources management

The history of human civilization is that of water development.(Hsiao Cheng-Tsung, 2004, pp. 17) The water is the element of life (Note 1), and development of human civilization is closely related to the supply of water, which is precious and limited. Its tremendous impact on people's livelihood, if not properly allocated and used 
(Note 2), will inevitably be plagued. Thus a nation's rise and fall has a lot to do with water. The United Nations officially declared at the end of 2002, "Having clean water is one of the fundamental to human rights (E-paper on Environmental Information, 2003)", "Water is one indispensable right to realize human dignity and health", and predicted that future wars will be waged caused by snatching water. Taiwan is a country founded on human rights, so the government has the responsibility to plan a set of water policies consistent with the spirit of sustainable development.

Since the retrocession of Taiwan, the development and utilization, operation and management of water resources and have had different points and strategies on the different stages (Ministry of Economic Affairs, 2006). From 1945 to 1964, the point was mainly to increase water sources during the dry season by constructing reservoirs and developing groundwater (Note 3), having significant results of rice crop and water conservancy. From 1973 to 1983, due to rapid industrial development and improvement of people's life, industrial and domestic water use had grown rapidly, during which the basic strategy was still to build more reservoirs. From 1984 to 1995, the main strategy was to have sufficient water supply for public use. Since 1995, the global trend has been towards strengthening the operation and management instead of unlimited water development. Water has played an important role in the process of economic construction and development in Taiwan. In other words, the development and utility of water resources has been perfectly related to our economic development. With abundant resources, "free water access" by the provisions of civil law is certainly out of question, but with the increasing water demand every year, the problem of water scarcity is growing more and more serious.

The water problem lies not only in rainfall but topography, climate, population, economic activities, and even water engineering also likely to lead to water shortages. Furthermore, it is about distribution, supply and management. (Li San-Wei, 1996) According to the definition of the United Nations, Taiwan belongs to the country lacking of water. Not belong to dry areas, Taiwan is still prone to drought partly because: With the social development, population growth, water demand is growing year by year. During a long-term low rainfall, drought would take place in certain areas, frequently leading to inconvenience of people's daily life, and damage of agriculture, commerce, industry and other industries. Especially in recent years, abnormal climate changes in Taiwan has caused extremely unstable rainfall, while the document also points out that in the past one hundred years global temperatures have tended to rise up. Such kind of change in rainfall and temperature may bring about insufficient rainfall due to abnormal climate changes in Taiwan, and thus frequent face of reservoirs short of water storage.

Therefore, the reasons of water shortage are to be explored in this article simply based on the shortage problems, proceeding with assessment and analysis response to strategies of water shortage.

\subsection{Research Questions}

Water issues lie in not merely the amount of rainfall but distribution, supply and management as well. (Yeh Feng-Mei, 2005) Water is a precious natural resource of mankind, not only directly used to sustain human life, but also indirectly for the industry and agriculture in order to protect and enrich human life. Water shortage has become an important issue of water resources in Taiwan. This article will focus on the factors and solving strategies of water shortage, discussing about following descriptions.

First, study constitutions of the water shortage factors from political economy, nature and management to make an overall analysis, and review relevant academic papers of advanced scholars and data reports of related units.

Second, from a managerial point of view explore the importance degree of water shortage factors so as to understand what factors are critical elements. Conduct a deep study on the factors of water shortage and assess the importance of the factors of water scarcity with AHP by means of questionnaires. Quantitative methods are adopted to improve the objectivity and rationality of the strategy planning, as the reference helping related personnel in water irrigation administrative agencies with the implementation of strategies and allocation of resources to the relevant personnel to assist water agencies to implement strategies and allocate resources as a reference.

Third, explore the crucial solving strategies and how to emphasize on both the conservative and developmental aspects in terms of the diversified development, rights, price and deployment of water resources.

Fourth, explore the relationship between the solving-strategies and factors of water shortage, and conduct the synthetic decision making of the above. Clarifying the relationship between strategies and factors will help to understand what strategies work more than others to solve water shortage in an overall view. From the result of the synthetic decision making, we can see which strategies are more important, which ones less, and strategies can be said as alternative means of factors, whose priority shows the contributive degree to the overall factors; 
the greater the contribution is, the greater the impact has on the overall performance. In other words, those with high contribution can be considered key strategies for the organization development. The organization staff should give more resource allocation to these strategies, and by enhancing the operational efficiency of them the overall management performance can be quickly improved.

\section{Literature Review}

\subsection{Literature Review of Taiwan's water scarcity}

Taiwan's water scarcity is not only an issue of the amount of rainfall, but also of the distribution, supply and management. There is no clear definition of being short of water. This study has defined it as the natural scarcity of water resources or the lack of supplies caused by mismanagement, which are different from the drought. The following are reviews and discussions of related researches:

First, Ouyang Chiao-hui (2006) says that, according to the assessment of Ministry of Economic Affairs, the development of new water sources is rather difficult, and that the lack of water will become the norm, and that we must establish the normal mechanisms for dealing with water scarcity because of the high-tech industries development in central and southern Taiwan, coupled with space-time distribution of rainfall.

Second, in terms of the compensation of the transfer of water rights, Chou Ch'ang-O's study (2002) suggests that in the face of water shortage the government agencies can allocate water rights and distribute it to meet the users' needs, and the transferred, such as the irrigation associations, should be compensated. Yang Yuan Jin (2005) also considered that during the time of the other subject of water shortage, the agricultural use of water can be transferred for non-agricultural use, for which the adjustment and compensation mechanisms should be established in order to enhance the added value of water.

Third, regarding the establishment of water market, Chen Ming Chien's study (2003, 30, 1-26) indicated the possibility of the establishment of water markets to alleviate the increasing frequency of random stress on water shortage. He also pointed out (Chen Ming Chien, 1996, 15, 1-9) that since people from Europe started emigrating to North America, the United States has established some systems in response to the management of water resource, which has evolved from the absolute ownership to the rules of priority allocation, in the hope that investors on water conservancy construction could obtain a stable investment insurance, giving rise to a higher willingness to invest, thus accepted by the society with free economy.

Fourth, in terms of the water price structure, Mu Yue Jun (2003) thinks that currently industrial, commercial and household users have been tariffed at a unified water price, while the benefits of water use in every walk of life differ greatly from the opportunity cost of water shortage. It is obvious that the rate is unfair. Although the tap water contains strong publicity, taking care of the issue of water price for people in remote areas, considering the social security system and tax policy to achieve the purpose of income distribution with the water price will cause the financial deterioration in water industry, doing harm to all the users.

Fifth, concerning the rebuilding of water conservancy administrative organizations, Lin Rui Qing (2002) examined the integrity of the management of the water resources with the theory of the rebuilding of the government organizations, while the current design of Taiwan's water conservancy administrative organization is used to neglecting the integrity, failing to take unified powers into consideration. Due to the non-uniform of powers among the central government departments relating to the powers and responsibilities of water authorities, such as the Council of Agriculture in charge of agriculture and water, Ministry of Economic Affairs in charge of industrial water, Ministry of the Interior in charge of water for people's livelihood, they all stand for their own advantages in the time of water shortage, while in which severe damage caused by flood, the central and local governments blame each other. The earliest policy delivered was to set up Water Department under the Executive Yuan.(Li Hung-Yuan, 1992) (Cheung Shek-Kok, 1995) (Chen Shu-Hui, etc., 1994, 30-37) considering Taiwan's political, cultural, institutional, environmental and other factors, it's thought that the most simple way is to form the integrated water conservancy dedicated department or administration to unify the powers. Taiwan's being without Ministry of Water Resources is one of the important reasons resulting in administrative issues on water conservancy. The problems on water actually arise from the departmentalism among all the units and unclear powers. It's necessary to proceed with the unified leadership in water powers in order to improve the domestic water use and the goal of sustainable development. (Lai Ho-Ming, 2004)

Sixth, in regard to the supply and deployment of water resources with a cross-regional cooperation, (Wang Te-Hsing, 2002) (Yang Ming-Zhou, 2005) Cheng Shih-han (2005, 76-82) pointed out that to solve the water supply problem must fix up with each others' needs among different counties and cities, which is the so-called "water transfer". In sufficient quantity it's not a problem, while in drought the phenomenon of "competition for 
water" would come out. In such situation, as a result, the central and local government should deal with the water resources problem in a mutual way by the means of cross-regional cooperation.

Seventh, the study of Tsai Hsun-hsiung and Li Zhilun (2002) indicated that there are five measures of coping with water scarcity: (1) In accordance with the long-term hydrological observation data or the weather forecasting of the Weather Bureau, the water quantity to supply is to be estimated by evaluating the periodical flow of each important water system and the flow into each reservoir before the plum rain season. (2) Simulating the deployment of water in every district according to the water supply regions and their water sources will help make both ends meet in water regionally. Saving water policy or negotiating to transfer agricultural water is necessary if there is shortage. What's worse, cross-water transfer should be considered. (3) The reservoir dredging to remove silt costs a lot in usual times, while in drought due to the exposure of silt the authority should immediately deploy all emergency dredging equipment to dredge so as to increase water storage capacity and to raise the capability of water supply relatively. (4) The authority should establish a team in response to emergent victims according to Disaster Prevention and Relief Act and masters the allocation of water supply and demand to enforce the management of water rights and resources with the relevant provisions of the Water Act. (5) Practice water conservation measures. Water supply fails to reach in some at the end or highlands, so water-saving measures should inform the public of the adjustment of domestic water, and methods for water conservation and the necessary water storage should be widely disseminated.

\subsection{Study of the Current Situation of Taiwan's Water Scarcity}

\subsubsection{The characteristics of Taiwan's water resources}

Taiwan is a warm and humid island state surrounded by the sea with maritime tropical and sub-tropical climate in subtropical monsoon zone. The rainfall is very abundant up to $2500 \mathrm{~mm}$ the annual average, about 90 billion cubic meters of water resources in total. The average annual rainfall of Taiwan is 2.6 times that of the world, but the distribution of rainfall for each person per year is equal to only about as $1 / 5$ average as the world due to high population density. The comparison of the Taiwan Area and the world per capita distribution of rainfall and the amount of rainfall is shown in Figure 2-1. Abundant rainfall in Taiwan, yet the uneven distribution of regions and seasons the densely populated and steep terrain along with the physical environment short of water storage facilities, most of the rainfall quickly flowing into the sea all lead Taiwan to a case of water-poor countries.(Ministry of Economic Affairs, 2005) Identified based on United Nations standards, the distribution of the rainfall per person per year amounts to about 4,500 tons, only the $1 / 7$ of the global average (about 34,000 tons). Taiwan has been included as the world's 18th country being serious lack of water resources.

Taiwan's annual rainfall focuses mostly during May to October, roughly accounting for the $78 \%$ amount of the whole year, called the wet season. November to next April, little rainfall is equal to only $22 \%$ of a year, known as the dry season. During it the supply of water resources in all areas in Taiwan is sufficient, while seasonal water shortage problems remain in some regions during the dry season. Although the wet period is as long as six months, in the dry period water resources rely on the deployment of reservoir water supply by virtue of a short and rapid river flow due to narrow and steep terrains, which causes the main reason for Taiwan's water shortage.

\subsubsection{The status of the subject of water in Taiwan}

The subject of water in Taiwan, including agricultural one, industrial one and people's livelihood, its use trends from 1995 to 2004 as shown in Table 2-1 and Figure 2-2, there had been a upward trend in the people's livelihood water from 1995 to 2001, and it reached the highest level in 2001, declining and then falling even from 2002 to 2004; industrial water consumption is up to the highest level in 2000. As for agriculture water, closely related to total water consumption has been showing the constant trend. Currently the subject of water used in agriculture ranks highest, followed by people's livelihood water and industrial one. We can see from the water distribution in the proportion of each subject over the past decade that he agricultural use of water has been going on the decrease, while the other subjects of water have been increasing. The downward trend in agricultural water use has something to do with the Taiwan's joining of WTO.

As our society has been business-oriented, and the Government actively promotes couples to raise their fertility, it is estimated that future population growth rate continues to go up, and rather the pressure of increasing demand for people's livelihood water derived from population growth and the improving life standard must remain. Though the industrial water use, with Taiwan's economic construction and development, has been rising every year, in 2001 it showed a slight decline. In the following year of 2021, the estimate of water demand is shown in Figure 2-3, in which the agricultural water fell from 12.29 billion tons to 11.77 billion tons, while the other ones take on a rising trend, particularly the industrial water use by $11.5 \%$ increase. 


\subsubsection{The status of Taiwan's reservoirs (Note 4)}

In Taiwan currently are 89 main reservoirs in total(Ministry of Economic Affairs, 2006), but the total effective capacity is only about 2.243 billion cubic meters, having played a great effect to the water supply in the dry season in Taiwan, but there are still gaps between the objectives. Comparison of the total reservoirs among Taiwan, the United States, and Japan is shown in Table 2-2. To one's worry, the development of reservoirs has become much less easy than ever, and the location to build the reservoir has also become scarcer and the cost is very high. Faced with the ever-growing future demand for water, take into consideration the water resources environmental protection, to overcome the natural environment of Taiwan's water resources, and adapt to the negative impact of global changes in rainfall patterns caused by climate changes. Thus the rational use of water resources can be realized to meet the demand for future people's livelihood, the Industrial development and environmental conservation.

\section{Research Methodology}

\subsection{Analytic Hierarchy Process}

In this study, AHP (Analytic Hierarchy Process, referred to as AHP) used for assessing, a systematic approach of multi-attribute decision making (Multiple Criteria Decision Making) (Saaty, T.L., 1980, 30-45) can assess the subjective consciousness by means of the visualized level representation to demonstrate the relationship between structural elements of the decision-making problems. It can also effectively help decision-makers to determine a more rational quantitative judgments and comprehensive assessments, then leading to a more objective appraisal result to provide decision-makers with full program information so as to choose the appropriate guidelines or projects, and meanwhile reducing the risk of wrong decision-making.

Level analysis simplifies the complex issues to the easy structure of level system, to compare pairs of elements at all levels, quantifying to establish the pair-wise comparison matrix, in order to achieve the max feature value and vector as the priority vector of the level, or on behalf of the priorities orders among the various elements, and later using the consistency ratio analysis of AHP to assess the suitability of the contents of all the questionnaires to serve as a decision-making reference indicator.

\subsubsection{The purpose and assumptions}

The purpose of AHP is to systematize complex issues, giving level decomposition from different perspectives, and through quantitative methods, contextualizing to make a comprehensive assessment with a view to providing decision-makers an appropriate program to select. The basic assumptions of AHP mainly include the following:

(1). A system can be broken down into many types or elements, forming a network-like hierarchical structure. (2). Assume the elements of each level in hierarchical structure independent. (3). The elements within each level can be used as a threshold for evaluation from some or all of the elements in the last level. (4). In comparative assessment, the absolute scale can be converted into the proportion one. (5). After comparing pairs of elements at all levels, they can be processed with matrix of inverse value. (6). Not only does the relationship between the pros and cons satisfy the transitivity (If A is better than B and B is better than C, then A is better than C), while relationship of intensity also meet the transitivity (If $\mathrm{A}$ is twice better than $\mathrm{B}$ and $\mathrm{B}$ is three times better than $\mathrm{C}$, then A is six times better than C). (7). Perfect transitivity is not easy, so none-transitivity is allowed, but the extent of its consistency requires testing. (8). The degree of the strength of the elements are to obtain through the rule of the degree of the importance.

\subsubsection{The implementation procedure of AHP}

In the implementation of Analytic Hierarchy Process, its basic assumptions are: (a) A system can be expressed as a hierarchy. (b) Each element within each level can be evaluated by the threshold from the last level. (c) Comparative values between elements show positive and reciprocal relationship. (d) The hierarchies of elements are independent. In this study the implementation of AHP is decomposed to six steps, as shown in Figure 3-1.

\section{1). Confirm the structure of evaluative criteria}

Establish the hierarchical organizational structure of the criteria or project. Based on psychological constraints, the human brain can only deal with $7 \pm 2$ factors at the same time, and it would get into confusion when overloaded. Therefore, every hierarchy consists of no more than nine as the classification principle.

\section{2). Conduct a questionnaire survey}

Conduct a questionnaire survey with comparison of pairs. According to criteria or project level tree, use the elements of the same level to design the questionnaire survey of paired comparison. Conducting the survey on interviewed experts toward the relatively degrees of importance. The questions of the questionnaire form paired 
comparisons between every two elements, and the comparison of the elements should be evaluated by the threshold from the last level to conduct the paired comparisons among each other. If there are $\mathrm{N}$ factors, then it will take the $\mathrm{n}(\mathrm{n}-1)$ / 2 paired comparisons, the importance scales of the questionnaire are divided into 1 to 9 rating scales, detailed scales of the assessment criteria are shown in Table 3-1, including equally strong, a little stronger, quite strong, extremely strong, ultimately strong, relative to the numerical assessment of 1,3,5,7,9 and 2,4,6,8-scale referred to the adjacent intermediate values, The reciprocal value of the above indicates the importance of the latter than the former.

3). The establishment of paired comparison matrix

Obtain the results of the relative importance of the various elements according to the questionnaire, use the scale 1 to 9 along with its reciprocal, and build the paired comparison matrix $A=\left[a_{i j}\right]_{n \times n}$ in which " $\mathrm{n}$ " is the number of evaluation criteria, and the main diagonal is the self-comparative element, all equal to 1 , which means ${ }^{a_{i i}}=1$. Besides, the number of the triangle below amounts to the reciprocal of that above, which means $a_{i j}=1 / a_{j i}$ and $a_{i j}>0$, among which important degree $w_{i}$ of $a_{i j}$ on behalf of the criteria $i$ in relation to that $w_{j}$ of the criteria $j$, therefore, $a_{i j}=w_{i} / w_{j}$.Accordingly, the paired comparison matrix is available as follows:

$$
A=\left[\begin{array}{cccc}
\frac{w_{1}}{w_{1}} & \frac{w_{1}}{w_{2}} & \cdots & \frac{w_{1}}{w_{n}} \\
\frac{w_{2}}{w_{1}} & \frac{w_{2}}{w_{2}} & \cdots & \frac{w_{2}}{w_{n}} \\
\vdots & \vdots & \vdots & \vdots \\
\frac{w_{n}}{w_{1}} & \frac{w_{n}}{w_{2}} & \cdots & \frac{w_{n}}{w_{n}}
\end{array}\right]=\left[\begin{array}{cccc}
1 & a_{12} & \cdots & a_{1 n} \\
a_{21} & 1 & \cdots & a_{2 n} \\
\vdots & \vdots & \vdots & \vdots \\
a_{n 1} & a_{n 2} & \cdots & 1
\end{array}\right]
$$

4). Calculate the relative degree of importance

The use of paired comparison matrix can calculate the eigenvalues and eigenvectors; you can strike the importance of factors at all levels, calculating the maximum eigenvalue $\lambda_{\max }$ :

$A \cdot W=\lambda_{\max } \cdot W$

Then we can get the following determinant

$\operatorname{det}\left(\mathrm{A}-\lambda_{\max } \cdot \mathrm{I}\right)=0$

In which "I" as a unit matrix, calculate the eigenvectors $W=\left(w_{1}, w_{2}, \ldots, w_{n}\right)$, and thus the vectors of the importance of various elements will be obtained.

Among which: $\sum_{i}^{n} w_{i}=1$

In addition to the precise use of the maximal eigenvalue method, the approximate solution can be used to estimate the importance of the evaluation criteria, which formalizes the average value of the straight vector, also known as ANC method (average of normalized columns): First formalize each straight value, then sum up the horizontal elements, and last divided by the number of the each element. The calculating formula is defined as:

$w_{i}=\frac{1}{n} \sum_{j=1}^{n} \frac{a_{i j}}{\sum_{i=1}^{n} a_{i j}}, i, j=1,2, \ldots, n$

\section{5). Consistency test}

With regard to the vector of the degree of importance $W=\left[w_{i}\right]_{1 \times n}$, it is required to determine whether the assessment of decision-makers is the consistent. As a result, testing the consistency of the paired comparison matrix consistency is necessary. First, calculate the consistency vector, and then calculate the total vector of the importance degree, and its value amounts to the transferred matrix of vector of the importance degree multiplied by the paired comparison matrix $\mathrm{A}$, mathematical formula for

$$
C=\left[c_{i}\right]_{n \times 1}=A \cdot W^{T} \text { also }
$$




$$
C=A \cdot W^{T}=\left[\begin{array}{cccc}
1 & a_{12} & \cdots & a_{1 n} \\
a_{21} & 1 & \cdots & a_{2 n} \\
\vdots & \vdots & \vdots & \vdots \\
a_{n 1} & a_{n 2} & \cdots & 1
\end{array}\right] \cdot\left[\begin{array}{llll}
w_{1} & w_{2} & \cdots & w_{n}
\end{array}\right]^{T}=\left[\begin{array}{c}
c_{1} \\
c_{2} \\
\vdots \\
c_{n}
\end{array}\right],
$$

Then the consistency vector (CV) amounts to the transferred matrix of vector of the importance degree multiplied by the paired comparison matrix, and the mathematical formula is referred to:

$$
C V=\left[c_{i} / w_{i}\right]_{1 \times n}=\left[\begin{array}{llll}
c_{1} / w_{1} & c_{2} / w_{2} & \cdots & c_{n} / w_{n}
\end{array}\right],
$$

Then, calculate the consistency index(CI)

$$
C I=\frac{\lambda \max -n}{n-1}
$$

If $\mathrm{CI}=0$ means that the previous and posterior judge own a complete consistency, that is, the questionnaire respondents has made a complete consistency in the appraisal of factors for the criteria, which meets the condition of $a_{i j}=a_{i k} \cdot a_{k j}$, in line with the mathematical transitivity law, and the final calculation of consistency ratio (CR) to measure the consistency of the calculation method, defined as $\mathrm{CR}=\mathrm{CI} / \mathrm{RI}$, where "RI" is an average random consistency index. Table 3-2 shows that the value of RI will be decided by the orders of " $\mathrm{n}$ " of the paired comparison matrix of. If the calculation results in $\mathrm{CR} \leqq 0.1$, the errors are considered acceptable and tolerable, and consistency throughout the assessment process. Otherwise, the assessment process must be repeated until the consistency ratio can be accepted.

6). The integrated Importance degree

Calculate the degree of the final overall importance. The overall importance of the underlying elements is equal to the degree of the importance in its class, multiplied by each of its value of importance of the elements in each upward class.

In this study, the pro decision-analyzing software "Expert Choice 2000", has been used for the calculation of the secondary-level analysis, which can help organizations make better decisions and a variety of information can be integrated to provide the necessary capacity to analyze, prioritize processing and communicating these decisions. The software provides mathematically rigorous application and proven process in priorities and decision-making, simplifying the complex decisions into a series of paired comparison, and integrating the results of decision-making.

\subsubsection{The application of AHP in this paper}

1). In this study, the application of AHP to assess the importance of the factors resulting in water scarcity, and the use of the questionnaire to survey senior executive staff of water irrigation administrative agencies how they view about the appraisal of the importance degree of the factors resulting in water scarcity are both expected to obtain more objective results.

2). In this study the factors resulting in water scarcity have been consolidated through the literature review and have come out with eight key water factors, as the objects of AHP.

3). This study is intended to calculate by means of the pro decision-analyzing software "Expert Choice 2000" for the calculation of the secondary-level analysis, which in this case may end with more accuracy.

4). Through the regular treatment the overall importance of the AHP amounts to the value of "1"

5). The obtained results of the importance degree of water scarcity factors will be the comprehensive evaluation criteria for follow-up coping strategies in water scarcity and the accordance to weighted value.

\subsection{Synthetic decision making}

\subsubsection{The concept of the synthetic decision making analysis}

Because the same thing with multiple properties will be affected by many factors, in the evaluative process it is necessary to take these related factors into a comprehensive consideration in order to conduct an integrated assessment, which is the so-called "synthetic decision making" (Hc'ueh Sung-Lien, 1992). In the establishment of membership, or pattern recognition process, people will find the difficulties of the multi-factor evaluation. In real life, to estimate a certain thing often involves a number of factors or indicators. Estimation is a sort of synthetic decision making under the interaction of factors, and it is the basic part of the system. The human brain 
is talented for doing synthetic decision making in the complex situation. The purpose of the synthetic decision making is to reach an optimal evaluative result on the basis of a comprehensive consideration of all the factors.

3.2.2 The steps of the synthetic decision making analysis are described below:

1). Establish the factor set, which is an ordinary collection affecting a variety of factors of the object.

2). Establish the weight set. In the factor set the degree of importance of each factor is not the same. For responding to that, the various factors should be given a corresponding weight, formed by the set of weights into the weight factor sets, referred to as the weight set. The weights can be regarded as the importance of various factors on the degree of membership, and therefore, can be viewed as the subset of the factor set. All weights are not only generally subjectively determined based on the actual issues that people need, but also according to the method of established membership degree to be determined. The same factor, if you take the different weight, will lead to different final evaluative results.

3). Establish the judged set, an ordinary collection consisting of judged objects.

4). Identify the evaluative set, consisting of the results the judges may pose on the object (strategy). In this research make of various evaluation a relationship matrix is applied to establish the evaluative set, as shown in Table 3-4. Building the "relationship matrix" is intended to acknowledge the relationship between the factors and strategies in order to indicate the factors and address the relationship and degree of the links among strategies and that is, the factor through the relationship matrix can be converted into the strategy for actual implementation. The relationship matrix, therefore, can be used to assess the "linkage strength" of the relationship between factors and strategies. Each "matrix cell" is called a "relationship", which means a strategy for resolving the "contribution degree" of a factor. This is a kind of "many-to-many" relationship. The relationship assessment within the relationship matrix of can be based on the experience of a manager or the consideration of the statistical analysis data usually with numeric or symbols to indicate their relationships. In this study, the measurement scale(0-1-3-5-7-9) has been adopted, as shown in Table 3-4 and defined as follows: 0 indicates "no relationship", expressed as 0 , or a blank; 1 indicates "very weak relationship", or can be expressed as $\Delta ; 3$ indicates "weak relationship", or can be said of $\bar{\tau} ; 5$ indicates "medium relationship", expressed as $\oplus ; 7$ indicates "strong relationship", or can be symbolic of (○); 9 indicates "very strong relationship", or can be expressed as •. Relationship matrix derives from collecting the questionnaire information filled out by the examinees before calculating the arithmetic mean.

5). Through the synthetic decision making, overall assessment is available, providing clear and quantitative decision-making information for each strategy. To calculate the absolute strategic importance refers to the absolute strategic priority, namely, derived from the scale sum of the relationship between the factor and the strategy multiplied by the relative importance of various factors. The total score is called the contributive degree of the strategy that contributes to the overall factors. The larger the value indicates, the more important the strategy is and the greater the impact on satisfaction performance of solving factors is.

6). From the results of the synthetic decision making, we can understand which strategies are more important, while which ones are not. Strategy can be said to be alternative means of factors, and its priority indicates the contribution to the integrity of the factors; the larger the value indicates, the greater the impact on satisfaction performance is. In other words, these highly-contributive strategies can be seen as the key strategies of the organizational development. The staff should allocate more resources to these strategies, and the operational efficiency of these strategies can be enhanced to rapidly improve the overall management performance.

\subsubsection{Synthetic decision making analysis applied in this thesis}

1). This research uses synthetic decision making analysis to assess the strategy of the water shortage and the questionnaire to survey senior executive staffs of water irrigation administrative agencies how they view about the appraisal of the importance degree of the factors resulting in water scarcity are both expected to obtain more objective results.

2). The study of water policy is regarded as the synthetic decision making object through the literature review and the eight major water strategies after being comprehensively analyzed.

3). Synthetic decision making analysis is mainly for the purpose of comprehensively evaluating how the water strategies solve the factors, analyzed in the use of the relationship matrix by means of questionnaire.

4). The results derived from the synthetic decision making analysis all have been in normalization processing, and the total score is 1 .

5). The questionnaire of the synthetic decision making analysis shows as Appendix B. 


\section{The assessment of the factors of Taiwan's water shortage}

The purpose of this study is mainly to conduct a deep study on the factors of water shortage, and to assess the importance of the factors of water scarcity with AHP. Quantitative methods are adopted to improve the objectivity and rationality of the strategy planning, as the reference helping related personnel in water irrigation administrative agencies with the implementation of strategies and allocation of resources. Through the AHP the importance of the factors of water shortage will be obtained and the critical water shortage factors will be clarified as the priority ranking of the specific objectives.

\subsection{Questionnaire and operating procedure}

This study we assess the water shortage factors with the questionnaire, supplemented with interviews to explain how AHP works in the paired comparison for the water shortage factors to those who fill out the questionnaire in order to facilitate the questionnaire survey. We hope that the abundant acquirements and practical experience of senior executive staffs in water irrigation administrative agencies can help gather assessment information related to water shortage factors. This research, therefore, has considered these senior executive staffs of water irrigation administrative agencies as experts. And this method is based on several assumptions as follows:

1). The assessment of integrated groups is better than that of individual.

2). Anonymous questionnaire practices enable the answers of the participants to be more objective and rational.

3 ). It is a reasonable approach to use the knowledgeable seniors to subjectively judge the water scarcity factors.

4). Effective information gathered by a group of seniors is deemed to be correct and effective.

Therefore, the application to the method must take the following matters: (1). Clearly mark the use of the themes and methods so that the participants will understand the theme, the purpose of this method they should be aware of and the roles they play. (2). Carefully choose the participants, in addition to a diversified selection of participants, the application of the expert questionnaire survey needs to rely on expert judgments and intuition very greatly, so carefully choosing participants is the key for this method to be applied correctly. In addition to considering the professional quality, the familiarity and experience of the related issues, and the reliability accuracy and consistency of their judgments of the related matters are to be taken into account. (3). Strictly design and process the questionnaire. Participants anonymously participate in it so that they can answer in no hurry. Also, be careful of designing questionnaires and statistics, analyzing survey results to ensure the professional judgments of experts to fit the purpose of professional information as a basis for the agenda setting.

\subsection{The subjects of the questionnaire survey}

To gain effective results in this study, the survey targets senior business manager of water resources units, having certain social experiences and knowledge in water conservancy construction or management. The study has issued 45 questionnaires in total except for 8 ones which were not returned and incompletely filled out, so 37 questionnaires have been collected, and the correct response rate is $82 \%$.

Qualified questionnaires amount to 37 ones, the subjects include 28 boys and 9 girls, aged from 45 to 65 , with more than 15 years' seniorities. The subjects surveyed have been from the first River Bureau to the 10th River Bureau and the northern, central and southern Bureaus of Water Resources in the hope of forming a group decision-making from the senior experts and expecting to obtain more comprehensive and objective results through the questionnaire survey.

\subsection{The data collection and analysis of the questionnaire}

In this study, AHP has been applied to assess the importance of the water shortage factors and questionnaire has been used to survey how the senior staff of the Water Resources Administration view about the importance rating of the water shortage factors in order to obtain more objective results. Through the literature review in this study, the water shortage factors have been synthetically coordinated to eight major factors as the appraisal subjects in AHP. The 8 main factors are A. water reservoir sedimentation, B. raw water turbidity, C. ineffective soil and water conservation, D. reservoir eutrophication, E. leakage rate of water pipelines, F. water pollution, G. waste of water, $\mathrm{H}$. power overlap among the water authority administrative organizations.

In this study, the approximate solution ANC (Average of Normalized Columns) is adopted to calculate the relative weight of criteria, the mathematical formula is defined as follows:

$$
w_{i}=\frac{1}{n} \sum_{j=1}^{n} \frac{a_{i j}}{\sum_{i=1}^{n} a_{i j}}, i, j=1,2, \ldots, n
$$


Then the steps of AHP are:

1). Calculate $\sum_{i=1}^{n} a_{i j}$ equal to the Column Total. The sum of the first column: $1+1.97+2.92+\ldots+2.81=17.72$

The rest of the Column Total is also the analogue, and the results can be obtained as shown in Table 4-2:

2). Calculate $\frac{a_{i j}}{\sum_{i=1}^{n} a_{i j}}$, equal to the original rating value divided by the Column Total, such as the first cell equal to: $1 / 17.72=0.0564$. The rest is also the analogue, and above comes out Table 4-3.

3). Finally calculate the importance degree of each water shortage factor.

According to the formula: $w_{i}=\frac{1}{n} \sum_{j=1}^{n} \frac{a_{i j}}{\sum_{i=1}^{n} a_{i j}}$, that is, calculate the row average. For example, the degree of the factor "water reservoir sedimentation $\mathbf{A}$ " would be:

$(0.056+0.031+0.047+0.099+0.036+0.113+0.085+0.026) / 8=0.062$, and the rest is the analogue. Then the degree of each factor will be obtained, shown as Table 4-4.

4). Consistency Check is divided into five sub-steps:

Step 1: First calculate the Weighted Sum Vector, and the value is equal to the paired comparison matrix A multiplied by the transposed matrix of the demand weighted vector. The mathematical formula is $C=\left[c_{i}\right]_{n \times 1}=A \cdot W^{T}$,

$$
C=\left[\begin{array}{l}
0.526 \\
0.785 \\
1.652 \\
0.262 \\
1.636 \\
0.492 \\
3.019 \\
0.701
\end{array}\right]
$$

Step 2: Calculate the Consistency Vector, equal to the total weighted vectors divided by the corresponding demand weights. The mathematical formula is

$$
C V=\left[c_{i} / w_{i}\right]
$$

$$
C V=\left[\begin{array}{l}
8.533 \\
8.745 \\
9.373 \\
8.650 \\
9.138 \\
8.261 \\
9.338 \\
8.753
\end{array}\right]
$$

Step 3: Calculate the largest eigenvalue, which is equal to the average of the total Consistency Vector, calculated as follows: 


$$
\begin{aligned}
\lambda_{\text {max }} & =\left(\sum_{i=1}^{n}\left(c_{i} / w_{i}\right)\right) / n \\
& =(8.533+8.745+9.373+8.650+9.138+8.261+9.338+8.753) / 8 \\
& =8.849
\end{aligned}
$$

Step 4: Calculate the CI (Consistency Index), according to the formula

$$
C I=\left(\lambda_{\max }-n\right) /(n-1)=(8.849-8) / 7=0.121
$$

Step 5: Calculate the CR (Consistency Ratio) to measure the consistency, and we can gain the formula for $\mathrm{CR}=$ $\mathrm{CI} / \mathrm{RI}$. Due to $\mathrm{n}=8$, by looking up the table RI $=1.41$ is derived, and thus, $\mathrm{CR}=\mathrm{CI} / \mathrm{RI}=0.121 / 1.41=0.086$, $\mathrm{CR}<0.1$, meaning that paired comparison matrix has met the requirement of consistency and the extent of its bias is still within the range of tolerance. Namely, the ante and post evaluation and judgment on the importance of decision-making to the water shortage have taken on rationality and consistency, so the importance degrees of the factors obtained can be the basis for the subsequent research.

\subsection{Verifying the results of the data analysis}

To verify the accuracy of the results of questionnaire analysis by means of AHP, Expert Choice 2000 expert decision analysis software is applied for the secondary-level calculation to verify the result of the previous weight value, Expert Choice software provides rigorous mathematical applications and proven process of prioritizing and decision-making. First, have the paired comparison matrix in this study input it, the results shown in Figure 4-1.

The results of the importance rating obtained from using Expert Choice 2000 analysis software has been shown in Figure 4-2

\subsection{The result and discussion on the assessment of water shortage factors}

It has shown quite a close result with either the ANC or the application of Expert Choice 2000 Decision Analysis supporting the AHP, both of which are in compliance with the requirements of the consistency check. The assessment shows that the importance of the water shortage factor is in order of "waste of water" (0.337), " ineffective soil and water conservation " (0.181), "water pipeline leakage rate" (0.178), "raw water turbidity" (0.085), " power decentralized among the water authority administrative organizations " (0.077), "reservoir sedimentation" (0.058), "water Pollution" (0.055), "reservoir eutrophication" (0.029). Thus the higher ones can be regarded as critical water shortage issues, as the basis for ranking the priority of specific objectives and also as a reference for policy implementation in response to water shortage in Taiwan.

\section{The Synthetic Decision Making of The Strategy to Solve Water Shortage}

This section is to proceed with the synthetic decision making of the strategy to solve water shortage. From the result, we can see which strategies are more important, which ones less, and strategies can be said as alternative means of factors, whose priority shows the contributive degree to the overall factors; the greater the contribution is, the greater the impact has on the overall performance. In other words, those with high contribution can be considered key strategies for the organization development. The organization staff should give more resource allocation to these strategies, and by enhancing the operational efficiency of them the overall management performance can be quickly improved.

\subsection{Questionnaires and operating procedures}

In this research the questionnaire is used to address the synthetic decision making of water scarcity strategy, supplemented by interviews to explain the synthetic decision making procedures to those filling in the questionnaire, we hope to gather information related to water scarcity factor assessment from the senior members with rich cultivation and practical experience serving in water authorities. In this research, thus, we take these seniors serving in the water authorities as veteran experts. And this method is based on several assumptions:

1). Integrated group assessment is better than individual one.

2). An anonymous operation can make the answers of the survey repliers more objective and rational.

3). The use of knowledgeable seniors to judge the subjective assessment of water scarcity factors is a reasonable approach.

4). Information gathered by a group of experienced ones can be deemed to be correct and effective. 
Therefore, the application of this method must grasp the following matters: (1). Clearly mark the use of the subject and methods so that the participants can understand the theme, the purpose of this method they should be aware of and the roles they play. (2). Carefully choose the participants with a diversified selection of the participants. The application of the expert survey relies on expert judgments and intuition greatly, so carefully choosing participants is the key to proper application of this method. In addition to the professional quality, the related degrees of their familiarity and experience, the reliability, accuracy and consistency of their judgments related to the matters, are all required to be taken into account. (3). Anonymity will have the participants answer at ease. Also, be careful of the questionnaire design and statistical analysis of survey results so as to ensure the professional judgments of the experts with the purpose of professional information as a basis for the agenda-building.

\subsection{The subjects of the questionnaire}

To have effective results, the questionnaire is targeted at the senior managers of the water resource units, who own considerable social experience and knowledge on water construction and management. 45 copies of questionnaires had been sent out before the 38 ones of them returned except the other 7 copies unreturned and incompletely filled in, and the correct response rate was $84 \%$.

Qualified questionnaires amount to 37 ones, the subjects include 28 boys and 9 girls, aged from 45 to 65 , with more than 15 years' seniorities. The subjects surveyed have been from the first River Bureau to the 10th River Bureau and the northern, central and southern Bureaus of Water Resources in the hope of forming a group decision-making from the senior experts and expecting to obtain more comprehensive and objective results through the questionnaire survey.

\subsection{The data collection and analysis of the questionnaire}

The synthetic decision making of the strategy to solve water shortage consists of four steps: (1). First confirm the sets of the water shortage factors corresponding to the sets of the weights. Therefore, the degree of importance of each factor is not the same; the weights can be considered the subornation of each factor via the importance. The weights are generally subjectively identified according to people's demand of practical problems. Use the same factors with different weights, and then the final outcome of evaluation will be different. (2). Establish the evaluated set, which is a common set formed by the judged objects, while here is a solving strategy in response to water shortages. (3). Use questionnaires to identify evaluation set. Evaluation is the set consisting of the results the respondents have judged the solving strategy. The evaluation set is a relationship matrix, rated from 0 to 9 and divided into six levels, in which 0 indicates no relationship meaning the strategy has no contribution to the factor; 1 indicates very weak correlation, meaning the strategy has a very weak contribution to the factor; 3 indicates a weak correlation, meaning the strategy has a weak contribution to the factor; 5 indicates moderate correlation, meaning the strategy has a moderate contribution to the factor; 7 shows a strong correlation, meaning the strategy has a strong contribution to the factor; 9 indicates a very strong correlation, meaning the strategy has a very strong contribution to the factor. (4). Compile the survey results. After compiling questionnaire data of the relation matrix completed by the examinees and calculating the arithmetic mean, we can derive the relationship matrix, as shown in Table 5-9. (5). Consider the weights of the water shortage factors, and calculate the total score of the synthetic decision making of the strategy in response to the water shortage factors. (6). Process normalization in accordance with the total score of the synthetic decision making of the strategy, summing it up into 1. (7). Rank the normalized values, and the results have been shown in Table 5-1.

\subsection{The result and discussion of the synthetic decision making}

The factor with higher weights can be regarded as the critical water shortage reason, which the staff should be more concerned about. Problem-solving strategies are the way to solving the problem of water scarcity, so factors have to be connected with strategies, and reasonably more important factors should be more connected with the most water strategies. The solving strategy of water shortage can be therefore considered a substitute for, and the total score of the synthetic decision making shows the contribution for the overall water shortage factors. The larger the degree is, the stronger the solution will be. In other words, these highly- contributive solving strategies can be seen as the key items for the water conservancy staff to develop. The staff should allocate more resources to these solving strategies; that is, the focus of water resources development lies in the corresponding demand that has contributed more to the solution can be enhanced or improved by adopting these strategies, and then upgraded to solve the water shortage problem.

The synthetic decision making shows that the ranking order of the solving strategies lists as water resources dispatch (21.26\%), moderate development of water sources (18.56\%), water conservation promotion (14.73\%), adjustment of water rights system (14.02\%), adjustment of water prices ( $13.50 \%)$, rectification of water 
organizations $(9.26 \%)$, and maintenance of water pipelines $(8.66 \%)$. Obviously, the strategy of water resources dispatch has been viewed as the most important, which reflects the importance of mutual support of the island wide water resources along with the varying severity caused by different climatic factors, and furthermore the growing importance of water resource management. The second one is the appropriate development of water sources. Compared to other advanced countries, the water development in Taiwan still leaves something to be desired. With the effect of political factors and of rising environmental consciousness, it has yet to integrate all people's consensus before reaching the positive goal of source development. Waste of water is used to a serious problem in our country, so the strategy to promote water conservation in dry times will be at play to some extent, and in recent years water units have taken into certain effects promoting water conservation.

\section{The Conclusion and suggestion}

\subsection{The Research Findings}

Water is a precious natural resource of mankind, not only to sustain human life, but directly and indirectly used for the industry and agriculture to protect human survival and to enrich life. With gradually increasing water demand in recent years, however, difficult water development, human activities have caused imbalance of water supply and demand coupled with social economic activities and deforestation, leading to the loss of water reservation and reduction of groundwater and soil water; human activities cause water pollution, making less available water; serious waste of water leads to water shortages; river watershed reclamation, sand mining, and excessive pumping of farm groundwater damage conservative environment and capacity; all these factors have resulted in high demand of water resources, and difficult water development, causing water shortage. Water issues belong to not simply the amount of rainfall but also the problem of distribution, supply and management.

Water shortage problem has become an important issue on water resources in Taiwan, and the main purpose of this research, thus, is to do an in-depth study for the shortage factors along with the synthetic decision making to evaluate the importance of them. Use quantitative methods to enhance the objectivity and reasonability of strategy making as a reference for the relevant personnel in water agencies to implement strategies and allocate resources obtained by the AHP; following the results of the synthetic decision making can obtain critical water solving strategy also called the alternative means, and its priority shows the contribution levels of overall factors; the greater the strategy contributes, the greater the impacts on overall performance will be, so the strategy with a high contribution can be seen as the key one within organizational development. Organizational staff should allocate more resources to these strategies, which can be enhanced the operational efficiency to quickly improve the overall management performance.

According to the AHP to evaluate the importance of water shortage factors shows that the first more important ones list as the "waste of water", "ineffective soil and water conservation " and "leakage rate of water pipelines." The results of the synthetic decision making rank as " water resources dispatch " and "moderate development of water sources," "promotion of water conservation," and so on. Obviously, as problems of water shortage occurs, the perfect operation on the managerial mechanism of water resources dispatch matters first, and both the conservative and developmental strategies should be weighed the same.

\subsection{The suggestions}

The strategy of water resources dispatch is viewed as the most important among the respondents, which reflects the importance of mutual support of the island wide water resources along with the varying severity caused by different climatic factors, and furthermore the growing importance of water resource management. Drought in Taiwan does not necessarily occur everywhere at the same time, so existing reservoirs in series can be properly planned and zoned, to make the most effective use with effective mutual deployment and support, to relieve the disasters. However, comparatively the development of water resources by building new reservoirs may cost less but work faster. However, management personnel must be trained and mechanisms to facilitate the implementation have to be established as soon as possible. Most of the existing river water rights are acquired for agricultural water use. After joining WTO, the agricultural decline, farming waste and fallow would be inevitable, so apart from retaining the necessary water use, some water rights should be released as soon as possible for the needs of people's livelihood, industry, and ecology. As to the transferring compensation, it should be properly discussed and dealt with as soon as the government can.

Waste of water is used to a serious problem in our country, so the strategy to promote water conservation in dry times will be at play to some extent, and in recent years water units have taken into certain effects promoting water conservation. Concerning improving water use efficiency, the effective management of the existing water facilities is included. The active governance and conservation of watershed, processing reservoir dredging and improving the leakage rate of tap water can maintain the existing water supply ability, without the development 
of new water sources to fix up with the reservoir sedimentation or pipeline damage caused by the loss of water supply. From the supply side, through flexible joint use of the regional total water facilities water development can be reduced. In addition, we can be devoted to improving the efficiency of the surface water storage and deployment to increase the developing volume of water resources. The national industrial development and adjustment of industrial structure both play an critical role of supply and demand balance of water resources. It is also in need to discard the high water-consuming industry.

In order to give full play to the functions of the existing reservoirs, the Irrigation Department has currently proposed "Projects of reservoir update and improvement and watershed conservation", conducting dam improvements, reservoir dredging, reservoir watershed governance and protection, update and improvement of spillways and related facilities, which will help enhance the function of flood control and water storage of existing reservoirs, improve water quality, resume reservoir capacity and extend the life of them. Secondly, regarding the construction of the reservoir, one may also refer to the world's noted water expert, Professor Pan Guo-liang. In his program edited in China Times, Pun recommended that:

"Typhoon is synonymous with natural disasters, and we even had to use typhoon to enrich the water resource, which is much irony! We all know, the rainfall brought by typhoons is both heavy and dense, doing more harm than good. In addition to flood, it would cause serious soil erosion and reservoir sedimentation leading to life being cut short. The cost of dredging is far more than the economic value of water resources. Therefore, the management of water resources depends on the typhoon, which is not a very healthy idea. Taiwan's topographical and geological conditions are not easy to retain surface water, but we do have a natural underground reservoir (referring to inside the rock trays) with no exploration and development. What I want to emphasize here is the water inside the rock trays without after-effects of subsidence. The value of the underground reservoir lies in its very large storage space. Hereby take a simple example: fashionable spa wells can reach 1000 meters (that is $1 \mathrm{~km}$ ) deep. If the rock fissures accounts for 10 percent, within one square kilometer the whole rock can store 100 million tons of water far more than the effective storage capacity of Shihmen Reservoir (about 88 million tons). From the geological perspective, the aquifers worth development in Taiwan consist of rectangular sandstones and marbles. If we can find a few underground reservoirs, there is no worry about congenital defects such as the lack of dam, low utilization of surface water, whether the dry year is, not to mention relying on the arrival of the typhoon. "

The above is the proposed program by Professor Pan Guo-liang(2009), certainly worth reference for the units concerned when considering the construction of the reservoir.

\section{References}

Chen Ming-Chien. (1996). Dynamic Study of Water Rights Institutions. Engineering Environmental Bulletin, No. 15 , pp 1-9.

Chen Ming-Chien. (2003). Economic Analysis of Taiwan's Irrigation Water Rights and Water Market, (Agriculture and Economics), 30, 1-26, National Science Council Research Project NSC 86-2415-H-002-027, published by Department of Agricultural Economics, National Taiwan University.

Chen Shen-hsien. (2006). Study on Water Resources and Environment for the Industrial Development. Conference on Sustainable Development of Taiwan's Economy. International Convention Center of National Taiwan University Hospital, July 1, 2006.

Chen Shu-Hui, Li Yuan-Chuan, and Chen Chun-Lang. (1994). Exploration of Water Administrative and Managerial Organization. The Taiwan Water Conservancy, 42-2, pp 30-37.

Cheng Shih-han. (2005). Cross-domain Exploration of Unified Management of Water Resources - A Case Study of Taipei County and City. Master's thesis, Graduate School of Business Administration, Chung Hua University, pp. 76-82.

Cheung Shek-Kok. (1995). Water Development, Conflict and Compromise - the Theses Album of Six-Year Construction Plan and Water Resources Symposium. (1st ed.) Taipei City: China Times Publishing Co.

Chou Ch'ang-O. (2002). Exploration of Water Transfer Mechanism - Response to Water Shortage Problem in Taiwan. Seminar of Cross-strait Sustainable Development, Taipei Grand Hotel. (June 5-8, 2002).

Construction and Disaster Prevention Research Center, Feng Chia University. Annual Compilation of Water Statistics and the Total Reports of Livelihood Water Estimate, 2004. Water Resources Agency, Ministry of Economic Affairs, (Dec. 2005).

E-paper on Environmental Information. (2003). UN declaration: Water Is Basic Human Right. [Online] 
Available: http://e-info.org.tw/2003/01/0128/030128S.htm \# world2.

Hc'ueh Sung-Lien. (1992). Applied Fuzzy Mathematics. Taipei City: Scientific \& Technical Publishing Co., Ltd.

Hsiao Cheng-Tsung. (2004). The History, War and Future of Water Resources. (1st ed.). Taipei: Business Weekly Publications, Inc. pp. 17.

Lai Ho-Ming. (2004). Study on the Practicability of Centralized Powers and Management of Taiwan Water Resources Organization - A Case Study of Relevant Laws and Regulations. Master thesis, Institute of Political Science, National Taiwan Normal University.

Li Hung-Yuan. (1992). Exploration of Water Administration System, Civil and Water Engineering (Taipei), 19.3, pp 76-79.

Li San-Wei. (1996). Conservative Management of Reservoir Watershed. Second Cross-Strait Seminar on Water Resources and Technology, Institute of Technology: National Taiwan University. pp. 371-381.

Lin Jui-Ch'ing. (2002). Exploration of Functional Integration of Water Agencies in Taiwan - The Views of Reorganization, Master's thesis, Department of Public Administration and Policy, National Chi Nan University, (July 2002).

Mo Wen. (2004). Examine water Resources Management in Taiwan from the Water shortage Problem - Urgent Review of Regarding Reservoirs as the First Is in Need. [Online] Available: http://e-info.org.tw/issue/water/2004/wa04091001.htm.

Mu Yue-Jun. (2003). Privatization of Taiwan Water Industry - Analysis of the UK Experience. Master's thesis, On-job Program of Public Affairs, Tunghai University, (January 2003).

Ouyang Chiao-hui. (2002). The Forum on water shortage and drought-free. Times Cultural \& Educational Foundation. [Online] Available: http://www.chinatimes.org.tw/new/910505/drought-2.htm.

Pan Guo-liang. (2009). Natural underground reservoir, new water resources in Taiwan. [Online] Available: http://tw.myblog.yahoo.com/jw!bOq8.rCQAgIvSSOr6JC4L18byw--/article?mid=3703.

Saaty, T.L. (1980). The Analytic Hierarchy Process: Planning, Priority Setting, Resource Allocation. (1st ed.). New York: McGraw-Hill, pp. 30-45.

Tamkang University, Department of Water Resources Management and Policy Research Center, Water Resources Agency, Ministry of Economic Affairs. (2006). Evolution of Management and Policy. [Online] Available: http://www.water.tku.edu.tw/history4.asp.

Tsai Hsun-Hsiung \& Li Zhi-lun. (2002). Current Water Shortage Status and Countermeasures, National Political Comments. National Policy Foundation. Sustainable (Commentary) No. 091-001.

Wang Te-Hsing. (2002). Inter Local Government Cooperation in Taiwan--The Case Study of [Cross-border Cooperation of Kaohsiubg City, County and Pingtung]. Master's thesis, Institute of Political Science, National Sun Yat-sen University.

Water Resources Agency, Ministry of Economic Affairs. (2006). Data of Water Conservancy Information. [Online] Available: http://www.wra.gov.tw.

Yang Ming-Zhou. (2005). Exploration of Taiwan Water Resources Management Problem - Approach of Cross-domain Management, Master's thesis, Institute of Political Economy, NCKU.

Yang Yuan Jin. (2005). Study of Irrigation Association Operation Strategy in Response to environmental changes, Institute of China Rural Development Planning. Project Number: 94 agricultural-3.1-profit -01 (4).

Yeh Feng-Mei. (2005). Study of the Water Storage and the Utilization of Water Resources of Tseng Wen Reservoir. Master's thesis. Institute of Hydraulic and Ocean Engineering, NCKU. pp. 60.

\section{Notes}

Note 1. Water is the element of life, but not evenly distributes on the surface of the earth, while the ancient human civilization development and freshwater supply are closely related. Many large and small wars and armed fighting between villages or ethnic groups had also competed for the water resource.

Note 2. Paragraph 1, Article 18, Water Resources Act in accordance with different purposes of the access to water specifies the order of the water subject: 1. Domestic and public water use, 2. Agricultural water use, 3 . Hydraulic water use, 4. Industrial water use, 5. Water use of shipping, 6. other uses of water. It can be used to determine the priorities of water use during the drought. The Art. 12 states: "As a dispute over the registration of 
water rights happens due to lack of water, the order of the water subject will determine the priority...... ."

Note 3. Pursuant to the Water Act Implementary Provisions NO. 5, the reservoir refers to the water resource use or significant flood control, such as the weir, dam, artificial lake and its ancillary facilities and storage areas, and those declared by the central authority. There are 89 reservoirs in Taiwan now.

Note 4. The reservoir was not defined in relevant laws and regulations in the past, just named as "reservoir", but according to the definition of section 9, Water Resources Act, there are "Water storage referred to in Article 3 of this Act means the construction of the weir or dam with more than 3 meters in height or depth on or under the ground or ground water constituting a reservoir, its storage capacity over 2 million cubic meters." The basic facilities and equipment Constituting a reservoir are mainly the dam, spillway, outlet, sand escape, control water gate, water-clear pool, etc.. The engineering set differs with different factors such as the characteristics of catchment areas, the choice of the form of weir or dam, and subjects for water use.

Table 2-1. The profile of the subject of water consumption trends in Taiwan 1995-2004

\begin{tabular}{|c|c|c|c|c|c|c|c|}
\hline \multirow[t]{2}{*}{ Item } & \multirow[b]{2}{*}{$\begin{array}{l}\text { Total annual } \\
\text { water } \\
\text { consumption }\end{array}$} & \multicolumn{2}{|c|}{ Agricultural water use } & \multicolumn{2}{|c|}{ Industrial water use } & \multicolumn{2}{|c|}{$\begin{array}{ll}\text { People's } & \text { livelihood } \\
\text { water use } & \end{array}$} \\
\hline & & $\begin{array}{l}\text { water } \\
\text { consumption }\end{array}$ & $\begin{array}{l}\text { The } \\
\text { percentage in } \\
\text { total water } \\
\text { consumption }\end{array}$ & $\begin{array}{l}\text { water } \\
\text { consumption }\end{array}$ & $\begin{array}{l}\text { The } \\
\text { percentage } \\
\text { in total } \\
\text { water } \\
\text { consumption }\end{array}$ & $\begin{array}{l}\text { water } \\
\text { consumptio } \\
\text { n }\end{array}$ & $\begin{array}{l}\text { The } \\
\text { percentage } \\
\text { in total } \\
\text { water } \\
\text { consumptio } \\
\text { n }\end{array}$ \\
\hline 84 & 189.2 & 145.5 & 76.9 & 16.3 & 8.6 & 27.5 & 14.5 \\
\hline 85 & 181.2 & 135.0 & 74.5 & 17.7 & 9.7 & 28.6 & 15.8 \\
\hline 86 & 180.3 & 135.1 & 74.9 & 16.1 & 8.9 & 29.1 & 16.1 \\
\hline 87 & 168.8 & 122.6 & 72.6 & 17.0 & 10.1 & 29.3 & 17.3 \\
\hline 88 & 168.7 & 120.5 & 71.4 & 17.2 & 10.2 & 31.0 & 18.4 \\
\hline 89 & 178.1 & 123.1 & 69.1 & 18.7 & 10.5 & 36.3 & 20.4 \\
\hline 90 & 184.8 & 130.1 & 70.4 & 17.4 & 9.4 & 37.3 & 20.2 \\
\hline 91 & 186.9 & 134.1 & 71.7 & 17.7 & 9.4 & 35.2 & 18.8 \\
\hline 92 & 176.0 & 124.3 & 70.7 & 16.1 & 9.1 & 35.5 & 20.2 \\
\hline 93 & 177.8 & 126.0 & 70.9 & 16.5 & 9.3 & 35.3 & 19.8 \\
\hline
\end{tabular}

* Unit: 100 million cubic meters. 1 cubic meters of water $=1000$ liters of water $=1$ ton of water. Source: Water Resources Agency, Ministry of Economic Affairs: "Water Statistics Bulletin", website: http://www.wra.gov.tw/ public / PDF / 711114492671. pdf (visit date: May 25, 2007), page 1.

Table 2-2. Comparison of the total reservoir between Taiwan, the United States and Japan

\begin{tabular}{|l|l|l|}
\hline & $\begin{array}{l}\text { The sum of the } \\
\text { reservoir }\end{array}$ & $\begin{array}{l}\text { Total reservoir storage capacity } \\
\text { (million tons) }\end{array}$ \\
\hline The USA. & 82,704 & 135,000 \\
\hline Japan & 2,734 & 300 \\
\hline Taiwan & 89 & 22.43 \\
\hline
\end{tabular}

Source: Chen Shen-hsien (2006). 
Table 3-1. The Scale of the AHP Evaluation Criteria

\begin{tabular}{|l|l|l|}
\hline $\begin{array}{l}\text { Assessment } \\
\text { Scale }\end{array}$ & Definition & Description \\
\hline 1 & Equally important & $\begin{array}{l}\text { An equally important contribution for } \\
\text { two criteria or projects on the target }\end{array}$ \\
\hline 3 & $\begin{array}{l}\text { Experience and judgments show little } \\
\text { preference to a particular criteria or } \\
\text { project }\end{array}$ \\
\hline 5 & $\begin{array}{l}\text { Experience and judgments show strong } \\
\text { preference to a particular criteria or } \\
\text { project }\end{array}$ \\
\hline 9 & Very important & $\begin{array}{l}\text { Show actually strong preference to a } \\
\text { particular criteria or project }\end{array}$ \\
\hline $2,4,6,8$ & $\begin{array}{l}\text { Extremely important } \\
\text { preference for a particular criteria or the } \\
\text { project }\end{array}$ \\
\hline The reciprocal & $\begin{array}{l}\text { The importance of the } i \text { to that of the } j \\
\text { is the reciprocal of the importance of } \\
\text { the } j \text { to that of the } i .\end{array}$ & $\begin{array}{l}\text { The trade-offs between the } \\
\text { above-mentioned assessment scales }\end{array}$ \\
\hline Rational & $1.1 \sim 9.9$ & $\begin{array}{l}\text { The numerical scale extended to comply } \\
\text { with the consistency }\end{array}$ \\
\hline
\end{tabular}

Source: Saaty, cit., p.32-47.

Table 3-2. The RI (random index)

\begin{tabular}{|l|l|l|l|l|l|l|l|l|l|l|l|l|l|l|l|}
\hline Rank & 1 & 2 & 3 & 4 & 5 & 6 & 7 & 8 & 9 & 10 & 11 & 12 & 13 & 14 & 15 \\
\hline RI & 0 & 0 & $\begin{array}{l}0.5 \\
8\end{array}$ & 0.9 & $\begin{array}{l}1.1 \\
2\end{array}$ & $\begin{array}{l}1.2 \\
4\end{array}$ & $\begin{array}{l}1.3 \\
2\end{array}$ & $\begin{array}{l}1.4 \\
1\end{array}$ & $\begin{array}{l}1.4 \\
5\end{array}$ & $\begin{array}{l}1.4 \\
9\end{array}$ & $\begin{array}{l}1.5 \\
1\end{array}$ & $\begin{array}{l}1.4 \\
8\end{array}$ & $\begin{array}{l}1.5 \\
6\end{array}$ & $\begin{array}{l}1.5 \\
7\end{array}$ & $\begin{array}{l}1.5 \\
8\end{array}$ \\
\hline
\end{tabular}

Source: Saaty, cit., pp.12-65

Table 3-3. The structure of the relationship matrix

\begin{tabular}{||l|l|l|l|l|l|l||}
\hline \multirow{2}{*}{ Factor } & \multicolumn{5}{|l|}{ Strategy } \\
\cline { 3 - 8 } & Strategy 1 & Strategy 2 & Strategy 3 & $\ldots$ & Strategy n \\
\hline Factor 1 & Importance & $r_{11}$ & $r_{12}$ & $r_{13}$ & $\ldots$ & $r_{1 n}$ \\
\hline Factor 2 & Importance & $r_{21}$ & $r_{22}$ & $r_{23}$ & $\ldots$ & $r_{2 n}$ \\
\hline Factor 3 & Importance & $r_{31}$ & $r_{32}$ & $r_{33}$ & $\ldots$ & $r_{3 n}$ \\
\hline$\ldots$ & $\ldots$ & & & & $\ldots$ & \\
\hline Factor $\mathrm{m}$ & Importance & $r_{m 1}$ & $r_{m 2}$ & $r_{m 3}$ & $\ldots$ & $r_{m n}$ \\
\hline \hline
\end{tabular}

Source: defined by the author 
Table 3-4. The measurement scale of the relationship matrix

\begin{tabular}{|l|l|l|}
\hline Semantic scale & Correspondent numerical scale & $\begin{array}{l}\text { Correspondent representative } \\
\text { symbol }\end{array}$ \\
\hline no relationship & 0 & $\circ$ \\
\hline very weak relationship & 1 & $\Delta$ \\
\hline weak relationship & 3 & ¿ \\
\hline medium relationship & 5 & $\oplus$ \\
\hline strong relationship & 7 & $\bigcirc$ \\
\hline very strong relationship & 9 & $\bullet$ \\
\hline
\end{tabular}

Source: defined by the author

Table 4-1. The paired comparison matrix of the water shortage factors

\begin{tabular}{|c|c|c|c|c|c|c|c|c|}
\hline Factors & $\mathbf{A}$ & B & C & D & $\mathbf{E}$ & $\mathbf{F}$ & G & $\mathbf{H}$ \\
\hline $\begin{array}{l}\text { water reservoir } \\
\text { sedimenta-tion } \\
\text { A }\end{array}$ & 1 & $1 / 1.97$ & $1 / 2.92$ & 2.9 & $1 / 3.89$ & 2.02 & $1 / 4.29$ & $1 / 2.81$ \\
\hline $\begin{array}{ll}\text { raw } & \text { water } \\
\text { turbidity } & \\
\text { B } & \end{array}$ & 1.97 & 1 & $1 / 3.78$ & 2.88 & $1 / 4.55$ & 2.9 & $1 / 5.31$ & 2.09 \\
\hline $\begin{array}{l}\text { ineffective soil } \\
\text { and water } \\
\text { conservati-on } \\
\text { C }\end{array}$ & 2.92 & 3.78 & 1 & 4.63 & 1.99 & 3.76 & $1 / 4.17$ & 1.98 \\
\hline $\begin{array}{l}\text { reservoir } \\
\text { eutrophica-tion } \\
\text { D }\end{array}$ & $1 / 2.9$ & $1 / 2.88$ & $1 / 4.63$ & 1 & $1 / 6.55$ & $1 / 3.84$ & $1 / 5.45$ & $1 / 2.05$ \\
\hline $\begin{array}{l}\text { leakage rate of } \\
\text { water pipelines } \\
\text { E }\end{array}$ & 3.89 & 4.55 & $1 / 1.99$ & 6.55 & 1 & 2.92 & $1 / 2.83$ & 2.92 \\
\hline $\begin{array}{l}\text { water pollution } \\
\mathbf{F}\end{array}$ & $\begin{array}{l}1 / 2.0 \\
2\end{array}$ & $1 / 2.9$ & $1 / 3.76$ & 3.84 & $1 / 2.92$ & 1 & $1 / 3.01$ & $1 / 2.05$ \\
\hline $\begin{array}{l}\text { waste of water } \\
\text { G }\end{array}$ & 4.29 & 5.31 & 4.17 & 5.45 & 2.83 & 3.01 & 1 & 4.6 \\
\hline $\begin{array}{l}\text { power overlap } \\
\text { among the } \\
\text { water authority } \\
\text { administra-tive } \\
\text { organizati-ons } \\
\text { H }\end{array}$ & 2.81 & $1 / 2.09$ & $1 / 1.98$ & 2.05 & $1 / 2.92$ & 2.05 & $1 / 4.6$ & 1 \\
\hline
\end{tabular}

Source: the questionnaire data coordinated by the author 
Table 4-2. The results of each column total

\begin{tabular}{|l|l|l|l|l|l|l|l|l|}
\hline Factors & A & B & C & D & E & F & G & H \\
\hline $\begin{array}{l}\text { Column } \\
\text { Total }\end{array}$ & 17.72 & 16.32 & 7.27 & 29.30 & 7.13 & 17.92 & 2.75 & 13.92 \\
\hline
\end{tabular}

Source: the questionnaire data coordinated by the author

Table 4-3. Calculation of the cell and row average

\begin{tabular}{|c|c|c|c|c|c|c|c|c|}
\hline Factors & A & B & C & D & $\mathbf{E}$ & $\mathbf{F}$ & G & H \\
\hline $\begin{array}{l}\text { water reservoir } \\
\text { sedime-ntation } \\
\text { A }\end{array}$ & 0.056 & 0.031 & 0.047 & 0.099 & 0.036 & 0.113 & 0.085 & 0.026 \\
\hline $\begin{array}{ll}\text { raw } & \text { water } \\
\text { turbidity } & \\
\text { B } & \end{array}$ & 0.111 & 0.061 & 0.036 & 0.098 & 0.031 & 0.162 & 0.069 & 0.150 \\
\hline $\begin{array}{lr}\text { ineffective } & \text { soil } \\
\text { and } & \text { water } \\
\text { conser- } & \\
\text { vation } & \\
\text { C } & \end{array}$ & 0.165 & 0.232 & 0.138 & 0.158 & 0.279 & 0.210 & 0.087 & 0.142 \\
\hline $\begin{array}{l}\text { reservoir } \\
\text { eutroph- } \\
\text { ication } \\
\text { D }\end{array}$ & 0.019 & 0.021 & 0.030 & 0.034 & 0.021 & 0.015 & 0.067 & 0.035 \\
\hline $\begin{array}{l}\text { leakage rate of } \\
\text { water pipelines } \\
\mathbf{E}\end{array}$ & 0.220 & 0.279 & 0.069 & 0.224 & 0.140 & 0.163 & 0.129 & 0.210 \\
\hline $\begin{array}{l}\text { water pollution } \\
\text { F }\end{array}$ & 0.028 & 0.021 & 0.037 & 0.131 & 0.048 & 0.056 & 0.121 & 0.035 \\
\hline $\begin{array}{l}\text { waste of water } \\
\mathbf{G}\end{array}$ & 0.242 & 0.325 & 0.574 & 0.186 & 0.397 & 0.168 & 0.364 & 0.330 \\
\hline $\begin{array}{l}\text { power overlap } \\
\text { among the } \\
\text { water authority } \\
\text { adminis-trative } \\
\text { organiz-ations } \\
\text { H }\end{array}$ & 0.159 & 0.029 & 0.070 & 0.070 & 0.048 & 0.114 & 0.079 & 0.072 \\
\hline
\end{tabular}

Source: the questionnaire data coordinated by the author

Table 4-4. The importance degrees of the water shortage factors

\begin{tabular}{|l|l|l|}
\hline Factor & Degree & Rating \\
\hline water reservoir sedimentation A & 0.062 & 6 \\
\hline raw water turbidity B & 0.090 & 4 \\
\hline ineffective soil and water conservation $\mathbf{C}$ & 0.179 & 2 \\
\hline
\end{tabular}




\begin{tabular}{|l|l|l|}
\hline reservoir eutrophication $\mathbf{D}$ & 0.030 & 8 \\
\hline leakage rate of water pipelines $\mathbf{E}$ & 0.176 & 3 \\
\hline water pollution $\mathbf{F}$ & 0.060 & 7 \\
\hline waste of water $\mathbf{G}$ & 0.323 & 1 \\
\hline $\begin{array}{l}\text { power decentralized among the water } \\
\text { authority administrative organizations } \mathbf{H}\end{array}$ & 0.080 & 5 \\
\hline
\end{tabular}

Source: the questionnaire data coordinated by the author

Table 5-1. The relationship matrix and the synthetic decision making of the strategy in response to the water shortage factors

\begin{tabular}{|c|c|c|c|c|c|c|c|c|}
\hline \multirow[b]{2}{*}{ Factors } & \multicolumn{8}{|c|}{ The strategy in response to the water shortage } \\
\hline & Weights & $\begin{array}{l}\text { Water } \\
\text { conserv- } \\
\text { ation } \\
\text { promoti- } \\
\text { on }\end{array}$ & $\begin{array}{l}\text { Proper } \\
\text { exploitat-i } \\
\text { on } \\
\text { water } \\
\text { resource }\end{array}$ & $\begin{array}{l}\text { Water } \\
\text { pipeline } \\
\text { mainten- } \\
\text { ance }\end{array}$ & $\begin{array}{l}\text { Water } \\
\text { price } \\
\text { adjustm- } \\
\text { ent }\end{array}$ & $\begin{array}{l}\text { Water } \\
\text { rights } \\
\text { adjustm- } \\
\text { ent }\end{array}$ & \begin{tabular}{|l|} 
Water \\
resourcere \\
dispat- \\
ch
\end{tabular} & \begin{tabular}{|l} 
Water \\
organizat- \\
ions \\
rectificat- \\
ion
\end{tabular} \\
\hline $\begin{array}{l}\text { Reservoir } \\
\text { sediment- } \\
\text { ation }\end{array}$ & 0.058 & & & & & & & 3.03 \\
\hline $\begin{array}{l}\text { Raw water } \\
\text { turbidity }\end{array}$ & 0.085 & & & & & & 7.13 & \\
\hline $\begin{array}{l}\text { Ineffective } \\
\text { soil and } \\
\text { water } \\
\text { conservat- } \\
\text { ion }\end{array}$ & 0.181 & & & & & & 5.11 & 4.65 \\
\hline $\begin{array}{l}\text { Reservoir } \\
\text { eutrophic- } \\
\text { ation }\end{array}$ & 0.029 & & 5.32 & & & & & \\
\hline $\begin{array}{l}\text { Water } \\
\text { pipeline } \\
\text { leakage rate }\end{array}$ & 0.178 & & 5.06 & 8.56 & & & & \\
\hline $\begin{array}{l}\text { Water } \\
\text { Pollution }\end{array}$ & 0.055 & & & & & & 3.02 & 3.41 \\
\hline $\begin{array}{l}\text { Waste } \\
\text { water }\end{array}$ & 0.337 & 7.69 & 6.56 & & 7.05 & 7.32 & 5.32 & \\
\hline $\begin{array}{l}\text { Power } \\
\text { decentrali- } \\
\text { zed among } \\
\text { the water } \\
\text { organizat- } \\
\text { ions }\end{array}$ & 0.077 & & & & & & 3.26 & 5.51 \\
\hline Total score & & 2.592 & 3.266 & 1.524 & 2.376 & 2.467 & 3.741 & 1.629 \\
\hline
\end{tabular}




\begin{tabular}{|l|l|l|l|l|l|l|l|l|}
\hline $\begin{array}{l}\text { Normalizat- } \\
\text { ion }\end{array}$ & & $14.73 \%$ & $18.56 \%$ & $8.66 \%$ & $13.50 \%$ & $14.02 \%$ & $21.26 \%$ & $9.26 \%$ \\
\hline Rank & 3 & 2 & 7 & 5 & 4 & 1 & 6 \\
\hline
\end{tabular}

Source: Coordinated by the author

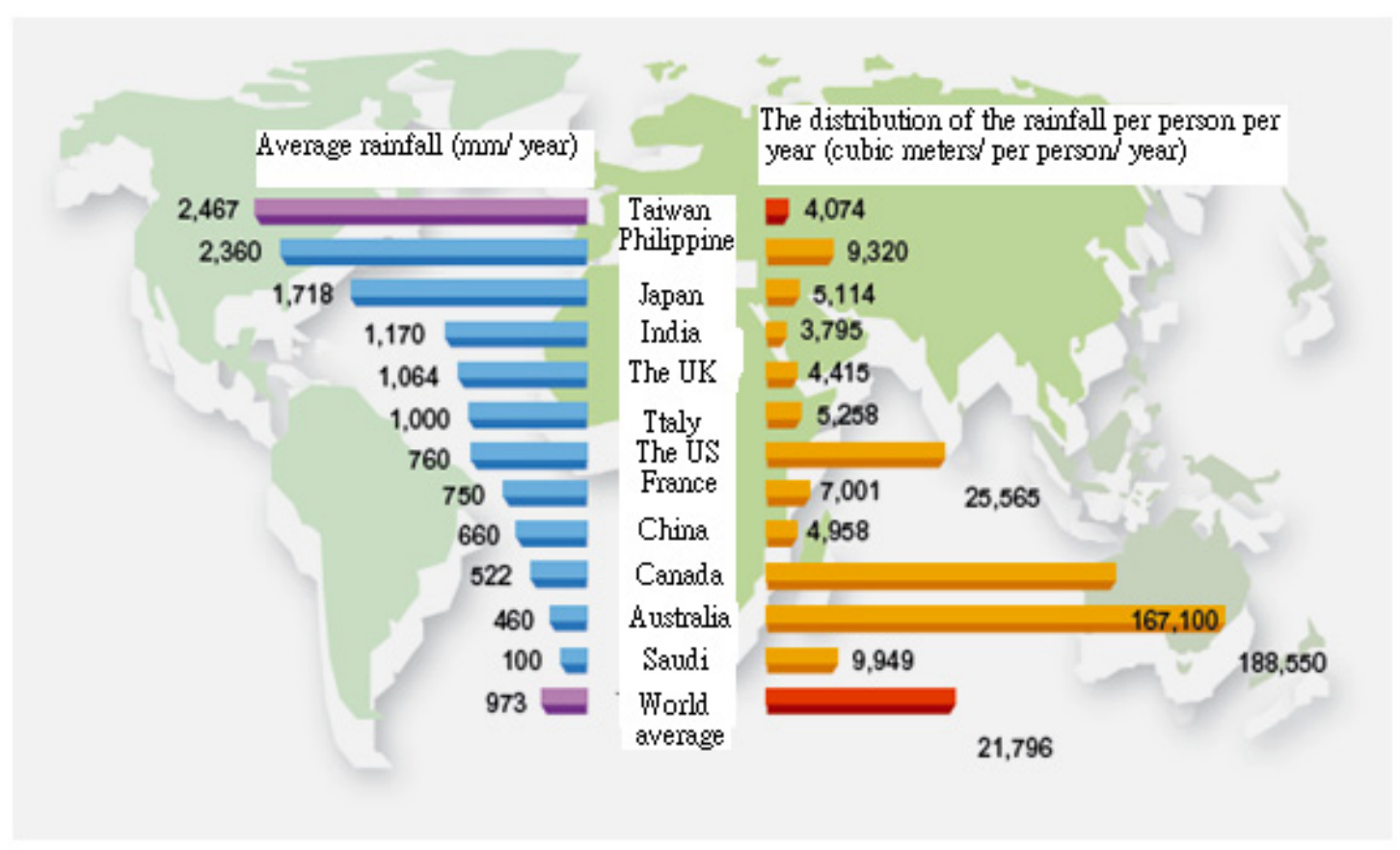

Figure 2-1. The comparison of the Taiwan Area and the world per capita distribution of rainfall and the amount of rainfall

Source: Chen Shen-hsien (2006) 


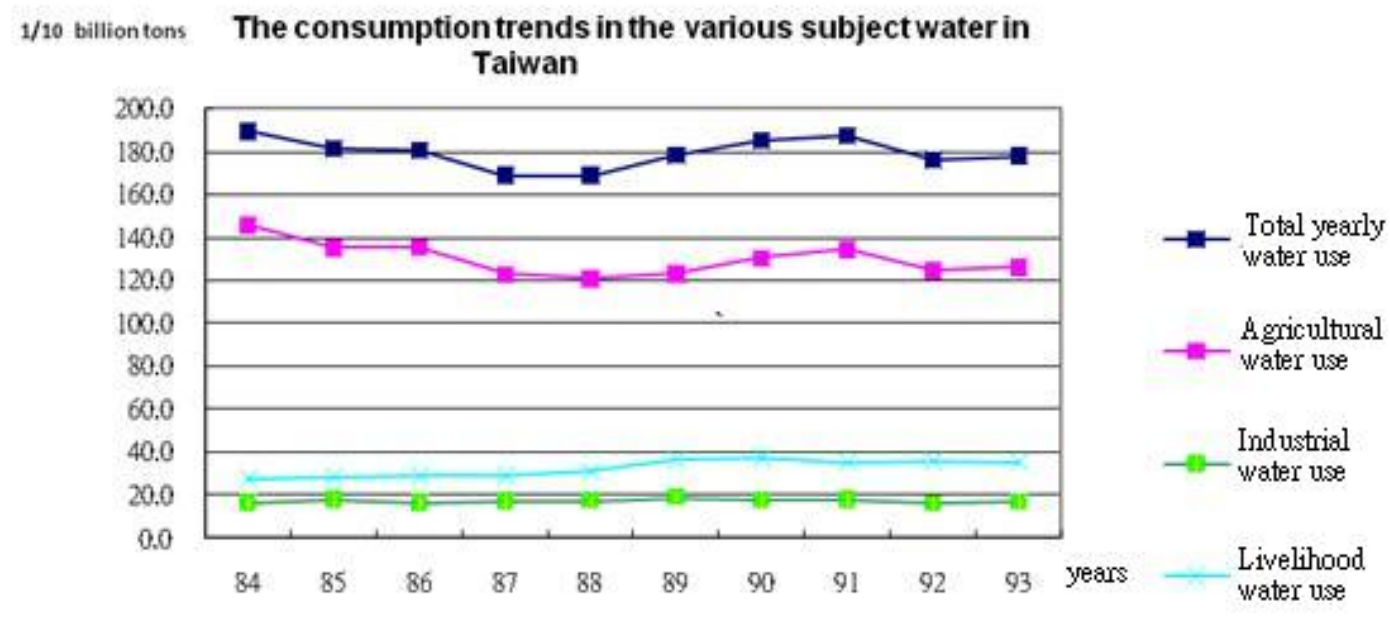

Figure 2-2. The water consumption trends in the various subject of water in Taiwan 1995-2004

Source: Water Resources Agency, Ministry of Economic Affairs: "Water Statistics Bulletin", website: http://www.wra.gov.tw/ public / PDF / 711114492671. pdf (visit date: May 25, 2007), Page 1

Present (Take 2001 as the criterion)

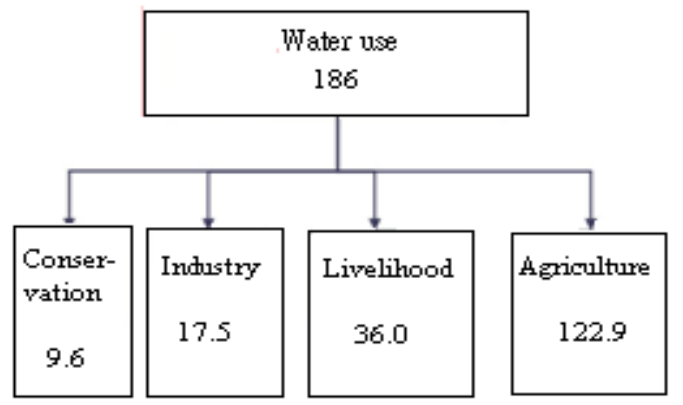

Total water demand

$=18.6$ billion tons
Predict the need of 2021

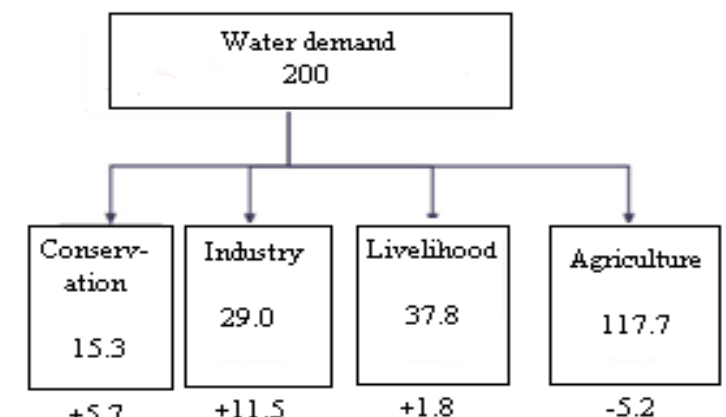

Total water demand

$=200$ billion tons

Figure 2-3. The subject of water consumption trends in Taiwan 1995-2004

Source: Chen Shen-hsien (2006) 


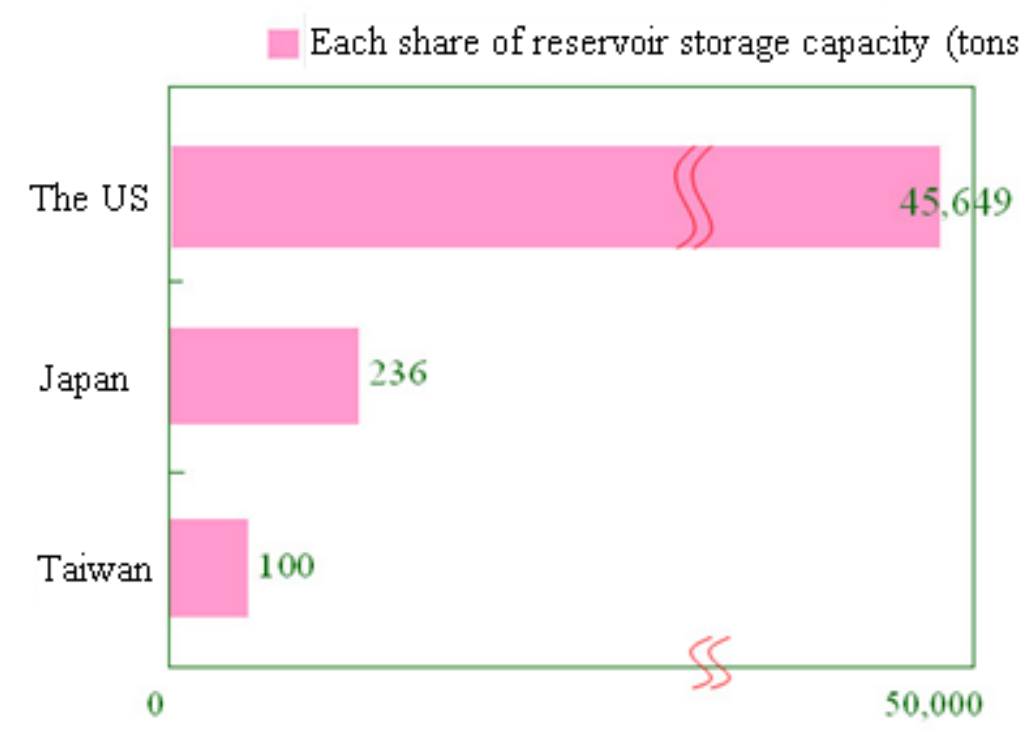

Figure 2-4. Comparison of each share of reservoir storage capacity

Source: Japan Ministry of Land Province, "Japan's Water Resources", 2005

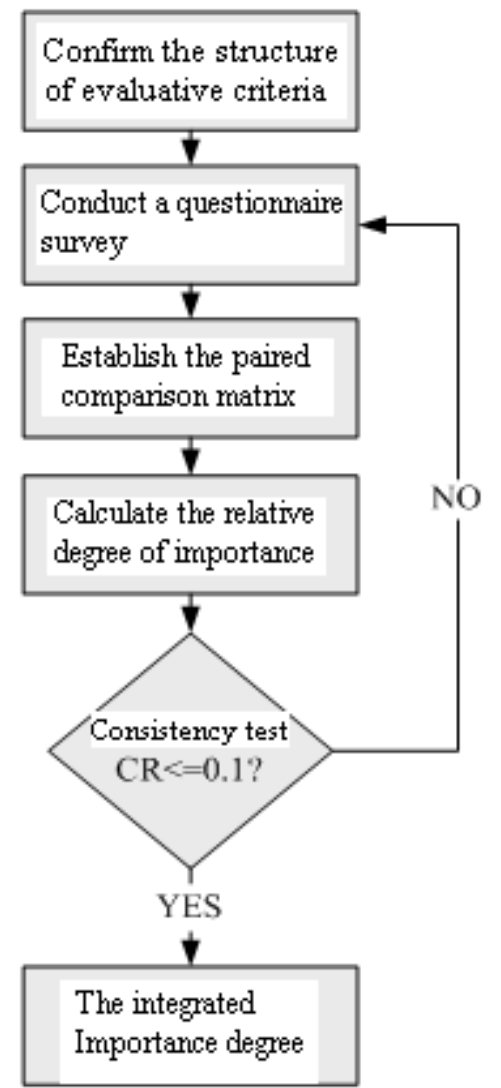

Figure 3-1. The implementation procedure of AHP

Source: made by the author 


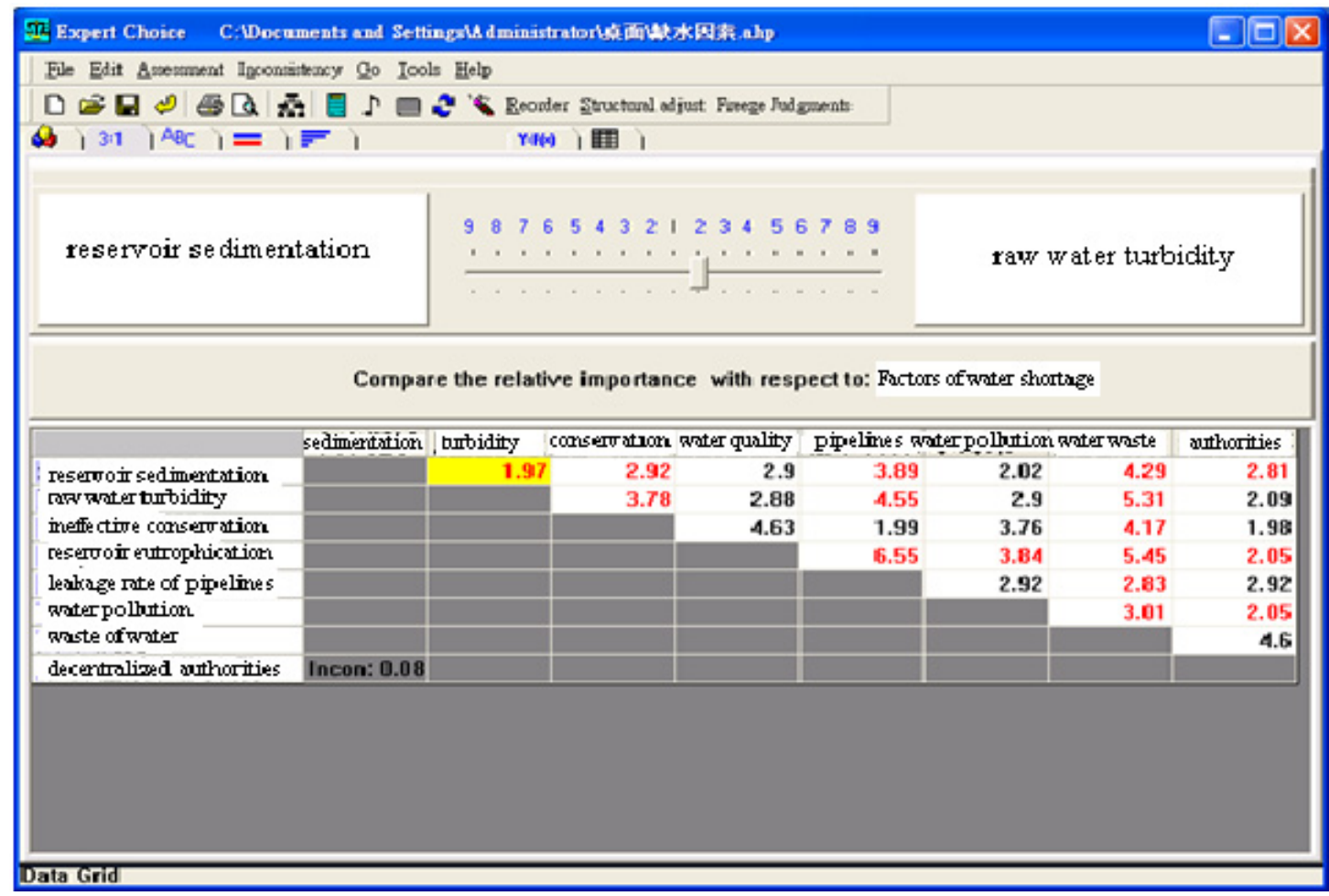

Figure 4-1. The case of AHP Questionnaire Data input Expert Choice

Source: Analysis from the Expert Choice 2000 of the input screen by the author

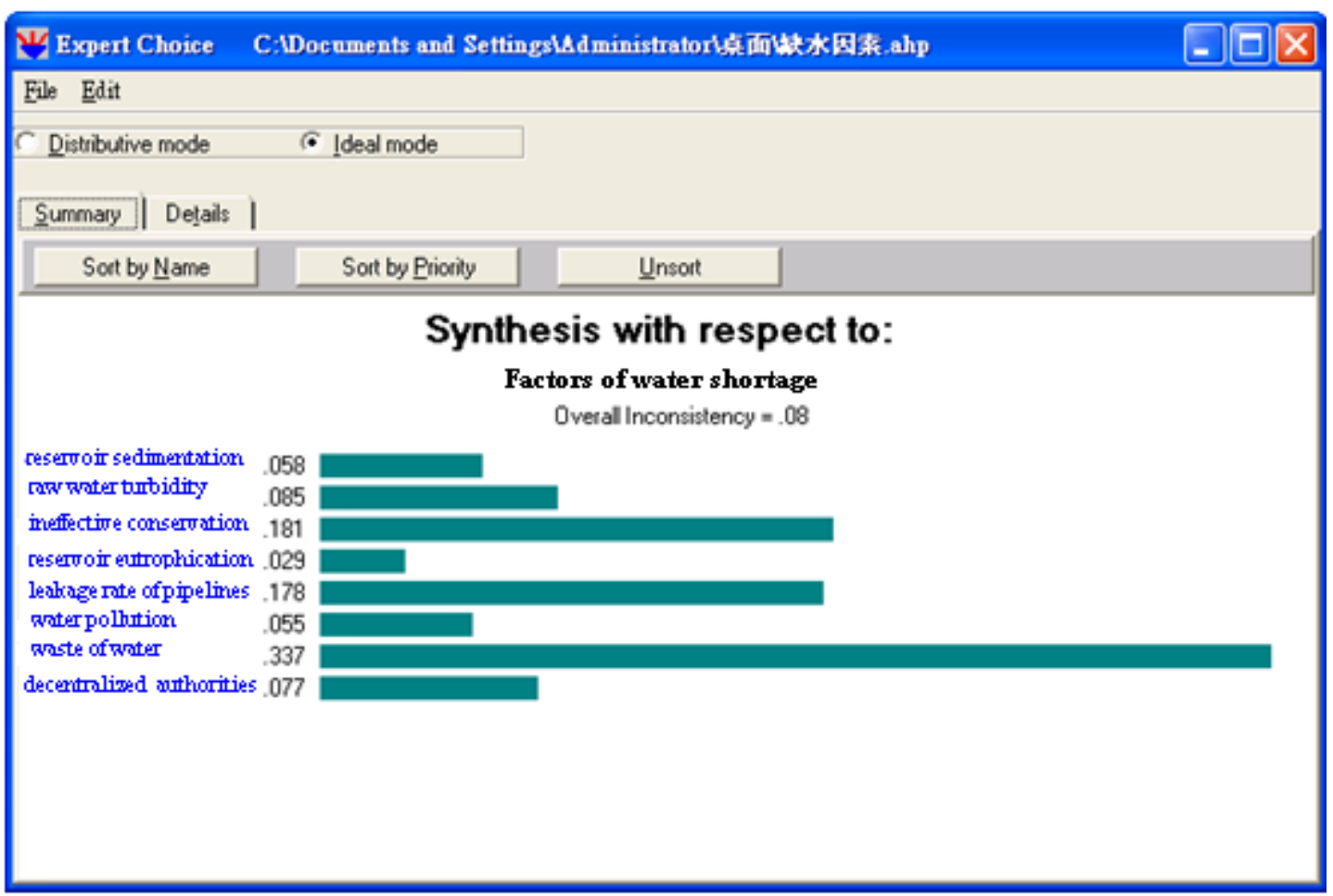

Figure 4-2. The results of the importance rating obtained from using Expert Choice 2000

Source: Analysis from the Expert Choice 2000 of the input screen by the author 